\title{
The continuing medical education needs of anaesthetists
}

Learning needs assessment is the term applied to the process of identifying or diagnosing a learner's educational needs. It is the foundation of a systematic continuing medical education (CME) programme. Needs assessment has been identified as the most pressing problem of medical education directors in North America. Furthermore, the CME learning needs, interests or motivations of anaesthetists have never been studied. The amount of time and effort required for needs assessment is probably a major deterrent to this activity. The investigators adopted simple and straightforward means of assessing the "perceived learning needs" and topic interests of anaesthetists. Questionnaires were sent by mail to anaesthetists practicing in teaching and nonteaching hospitals in the Toronto area. The questionnaire presented a list of CME content areas. The respondents were asked to indicate on scale of 1 to 10 their Current Expertise, Ideal-Desired Expertise, and Interest-Motivation levels for each content area. Need Score for each content area was calculated by taking the difference between Ideal and Current Expertise responses. A total of 101/305 anaesthetists (29\%) responded to the survey. Most of the respondents had been in anaesthesia practice for less than ten years. Regional nerve block, acute pain control, and medicolegal considerations received high overall ranks in both the need and interest categories. Paediatric anaesthesia, anaesthesia for trauma surgery and thoracic anaesthesia had top ranks among the subspecialty fields. Regional anaesthesia techniques received higher need and interest ranks than intravenous and inhalational techniques. The learning needs of anaesthetists of a large urban centre have been identified, and this information is useful to CME planners.
"L'éducation a besoin d'évaluation »; cette affirmation s'applique au processus d'identification et de diagnostic des besoins éducatifs du lecteur: C'est la base d'un programme systématique d'éducation médicale continue (EMC). On a indentifié l'évalua. tion des besoins comme étant le probléme le plus urgent des directeurs d'éducation médicale de l'Amérique du Nord. De plus, les besoins, intérêts ou motivations d'éducation en EMC des anesthésistes n'ont jamais été étudiés. Le temps et l'effort requis dans l'évaluation des besoins est probablement l'empêchement majeur à cette activité. Les investigateurs ont adopté des moyens simples et directs pour l'évaluation des "besoins d'éducations perçus » et des sujets d'intérêts des anesthésistes. Les questionnaires ont été envoyés par la poste de des anesthésistes pratiquant dans des hôpitaux universitaires ou nonuniversitaires dans la région de Toronto. Les questionnaires présentaient une liste des sujets d'EMC. Les répondants devaient indiquer sur une échelle de 1 à 10 leur expertise actuelle, leur expertise désirée, ainsi que leur niveau de motivation pour chaque sujet. Un pointage des besoins pour chaque sujet était calculé en prenant la différence entre l'expertise actuelle et l'expertise idéale. Un total de 101 anesthésistes sur 305 (29\%) ont répondu au sondage. La majorité des répondants étaient en pratique anesthésique depuis moins de 10 ans. Les blocs régionnaux, le contrôle aigü de la douleur et les considérations médico-légales ont rę̧u des hauts pointages dans les catégories basoins et intérêts. L'anesthésie pédiatrique, l'anesthésie pour chirurgie traumatique et l'anesthésie thoracique ont eu des pointages élevés parmi les sous-spécialités. Les techniques d'anesthésie régionale ont reçu des pointages d'intérêts et de besoins plus élevés que les techniques intra-veineuses et par inhalation. Les besoins en éducation des anesthésistes d'un centre urbain important ont été identifiés, et cette information est utile à ceux qui planifie l'EMC.

Continuing Medical Education (CME) consists of those educational activities undertaken by physicians after the completion of formal undergraduate and postgraduate training, for the purpose of maintaining and upgrading their standards of knowledge, attitudes and practice. ${ }^{l}$ In North America it is recognized that CME is a substantial and seemingly disorganized enterprise. ${ }^{2}$

The systematic approach to $\mathrm{CME}$ as an educational process requires at least four basic steps. First, learning 
needs must be identified and prioritized. Next, learning objectives must be formulated, based on the identified and prioritized needs. A programme consistent with the needs and objectives must then be implemented. Lastly, the programme must be evaluated based on the same needs and objectives. ${ }^{3-8}$ Recently, the application of adult learning principles to $\mathrm{CME}$ has allowed investigators to apply to physicians certain general conclusions about adults as learners. ${ }^{9}$

An initial assessment of learning needs is the foundation of a sound CME programme. In spite of its importance, learning needs assessment has been identified by CME planners in North America as one of their main problem areas. ${ }^{7}$ What is a learning need? From the psychological point of view, a need is present when there is a discrepancy or gap between the way things ought to be and the way they are. ${ }^{6}$ Thus a learning need exists if there is a discrepancy between what the physician ought to know and what he/she currently knows.

In order to make more cost-effective use of our limited CME resources, planners of CME must be encouraged to develop programmes based on learning needs assessment data. Review of recent literature revealed that the CME needs and interests of anaesthetists have never been studied. Thus a learning needs survey of Toronto-based anaesthetists was conducted to identify the perceived learning needs of anaesthetists and to develop an instrument (questionnaire/software package) for learning needs assessment.

\section{Methods}

Institutional approval was obtained. Questionnaires were sent by mail to all practicing anaesthetists in teaching and non-teaching hospitals in Toronto. Respondents were promised anonymity and were not required to place their names on the questionnaire. Three weeks later the same questionnaire was sent out to everyone, together with a note reminding those who had not yet responded to the initial mailing to do so.

The questionnaire presented the respondents with a list of 39 continuing education content areas chosen to represent the entire spectrum of the field of anaesthesia. The list of content areas was developed by first constructing a general list of content areas based on two textbooks in anaesthesia namely: "An Introduction to Anesthesia: The Principles of Safe Practice"10 and "Anesthesia."1l The list was then shown to a number of anaesthetists for opinion and modification. A pilot study was conducted on 25 anaesthetists of the Toronto Western Division, Toronto Hospital. The final content area list was formulated based on feedback from the pilot study (Figure 1).

For the purposes of this study, ideal expertise of a specific content area was defined as the degree of skills

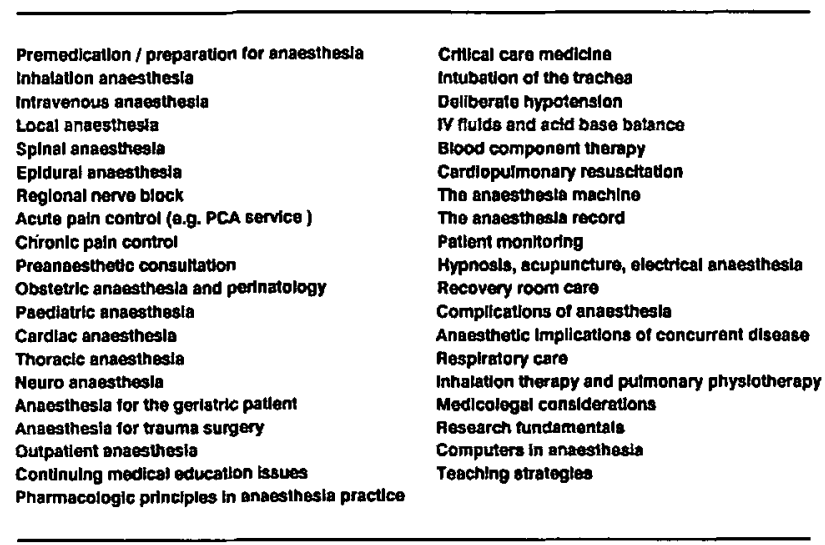

FIGURE 1 Continuing education content areas.

and knowledge the respondent would like to achieve in that content area. Similarly, current expertise in a specific content area was defined as the degree of skills and knowledge the respondent presently possesses in that content area. Learning need was defined as the difference between ideal and current expertise. ${ }^{7,8,12}$

The questionnaire was divided into four parts. Part I asked the respondent to indicate on a scale of 1 to 10 his/her current expertise in each of the given content areas. A score of 1 represented a minimum of expertise and a score of 10 represented the maximum. Part II asked the respondent to indicate on a scale of 1 to $10(1=\min 10=$ max) his/her ideal level of expertise in each of the given content areas. Part III asked the respondent to indicate again on a scale of 1 to 10 his/her interest or motivation in attending CME activities in each of the content areas. A score of 1 was to mean that he/she would not attend activities on that topic while a score of 10 meant that he/she would surely attend activities on that topic. Part IV contained four questions pertaining to the respondent's practice. (1) Number of years in practice. (2) Place of practice (teaching hospital, non-teaching hospital, both). (3) Type of practice (Full-time, Part-time). (4) Specialist (FRCPC) certification (yes, no).

The calculation of Perceived Need for each content area was obtained by subtracting current expertise scores from their corresponding ideal expertise scores (Perceived Need $=$ Ideal Expertise - Current Expertise) in order to measure the gap between current knowledge-skill and ideal knowledge-skill. ${ }^{7,8,12}$ The need scores for each content area represent the average score given by all respondents. Motivation score for each content area was calculated simply.by taking the average of all motivation scores given by respondents per content area.

In order to fulfil the second objective of the study, that of developing a quick and simple means of assessing learning need that could be made available to $\mathrm{CME}$ planners, a custom computer programme was developed. 
TABLE I Respondent profile*

\begin{tabular}{lccc}
\hline & \multicolumn{3}{l}{ Years in practice } \\
\cline { 2 - 4 } & $<10$ & $10-20$ & $>20$ \\
& 47 & 24 & 29 \\
\hline Place of practice & & & \\
Non-teaching hospital (51.3) & 19.7 & 10.5 & 21.1 \\
Teaching hospital (44.7) & 26.3 & 11.8 & 6.6 \\
Both (4.0) & 1.3 & 1.3 & 1.3 \\
& & & \\
Type of practice & & & \\
Full-time (88.1) & 40.8 & 21.1 & 26.3 \\
Part-time (11.8) & 6.6 & 2.6 & 2.6 \\
& & & \\
Specialty certification & & & \\
w/ FRCPC (84.2) & 42.1 & 18.4 & 23.7 \\
w/o FRCPC (15.8) & 5.3 & 5.3 & 5.3 \\
\hline
\end{tabular}

*All numbers expressed as percentage.

This programme can easily be customized to process any given list of content areas and automatically calculates perceived need and motivation score for each content area. It prints a list of content areas ranked by perceived need and by motivation score as well as a demographic data summary table.

\section{Results}

Of the 350 practicing anaesthetists in Toronto, 101 (29\%) responded to the survey. Thirty-five questionnaires were incompletely filled and had to be excluded from the analysis. The demographic data and practice profile are shown in Table I. Forty-seven per cent of respondents had less than ten years of anaesthesia practice; $24 \%$ had between 10-20 years of practice; and $29 \%$ had over 20 years of practice. Fifty-one per cent were based in nonteaching hospitals; $45 \%$ were from teaching hospitals and $4 \%$ practiced in both types of hospitals. Eighty-eight per cent of respondents practiced full-time while the other $12 \%$ were in practice part-time. Eighty-four per cent of respondents had specialty certification (Fellowship of Royal College of Physicians, Canada - FRCPC).

The perceived need for each content area was calculated by taking the difference between corresponding ideal and current expertise scores. Perceived need scores of each content area are shown in Table II. The Wilcoxon Signed Rank Test was used to see if the difference between ideal expertise and current expertise (perceived need) for each content area was significant. Results showed significance at the $P<0.05$ level for all content areas. The highest perceived needs were obtained in regional nerve block, acute pain control and medicolegal considerations. Comparing perceived scores between the top 19 and bottom 19 ranked content areas revealed significant difference between perceived need scores $(P<0.05)$.
TABLE II Ranking of content areas by perceived need scores

\begin{tabular}{ll}
\hline Content area & Need score \\
\hline Regional nerve block & 2.73 \\
Acute pain control (e.g., PCA service) & 2.69 \\
Medicolegal considerations & 2.49 \\
Chronic pain control & 2.25 \\
Critical care medicine & 2.20 \\
Statistical analysis, computers in anaesthesia & 2.20 \\
Anaesthetic implications of concurrent disease & 2.03 \\
Paediatric anaesthesia & 1.97 \\
Continuing medical education issues & 1.96 \\
Pharmacologic principles in anaesthesia practice & 1.88 \\
Complications of anaesthesia & 1.79 \\
Anaesthesia for trauma surgery & 1.78 \\
Thoracic anaesthesia & 1.75 \\
Inhalation therapy and pulmonary physiotherapy & 1.72 \\
Hypnosis, acupuncture, electrical anaesthesia & 1.71 \\
Teaching strategies & 1.66 \\
Respiratory care & 1.59 \\
Research fundamentals & 1.57 \\
Local anaesthesia & 1.54 \\
Blood component therapy & 1.50 \\
Preanaesthetic consultation & 1.49 \\
Cardiac anaesthesia & 1.47 \\
iv fluids and acid base balance & 1.43 \\
Cardiopulmonary resuscitation & 1.43 \\
Intravenous anaesthesia & 1.41 \\
Anaesthesia for the geriatric patient & 1.38 \\
Spinal anaesthesia & 1.33 \\
Neuro anaesthesia & 1.28 \\
The anaesthesia machine & 1.24 \\
Outpatient anaesthesia & 1.21 \\
Recovery room care & 1.16 \\
Obstetric anaesthesia & 1.13 \\
Epidural anaesthesia & 1.12 \\
Premedication and preparation for anaesthesia & 1.01 \\
Inhalation anaesthesia & 1.01 \\
Deliberate hypotension & 0.99 \\
Patient monitoring & 0.96 \\
Intubation of the trachea & 0.75 \\
The anaesthesia record & 0.72 \\
\hline & \\
\hline
\end{tabular}

The degree of interest of respondents in each content area is represented by its motivation score. Motivation score of each content area is shown in Table III. The highest motivation scores were obtained in anaesthesia for trauma surgery, anaesthetic implications of concurrent disease and complications of anaesthesia.

It was observed that paediatric anaesthesia, anaesthesia for trauma surgery and thoracic anaesthesia were the subspecialty fields that registered the highest need scores; while anaesthesia for trauma surgery, outpatient anaesthesia, and geriatric anaesthesia were the subspecialty fields of highest interest (Table IV). Regional anaesthesia techniques received higher need and interest ranks than intravenous and inhalational techniques (Table V).

When both Need and Interest Scores were summed together, there were ten CME Content Areas that consist- 
TABLE III Ranking of content areas by motivation score

\begin{tabular}{ll}
\hline & Motivation \\
Content area & score \\
\hline Anaesthesia for trauma surgery & 7.89 \\
Anaesthetic implications of concurrent disease & 7.62 \\
Complications of anaesthesia & 7.61 \\
Medicolegal considerations & 7.50 \\
Regional nerve block & 7.29 \\
Acute pain control (e.g., PCA service) & 7.26 \\
Outpatient anaesthesia & 7.21 \\
Critical care medicine & 7.17 \\
Anaesthesia for the geriatric patient & 6.96 \\
Thoracic anaesthesia & 6.89 \\
Intravenous anaesthesia & 6.87 \\
Blood component therapy & 6.87 \\
Cardiopulmonary resuscitation & 6.78 \\
Pharmacologic principles in anaesthesia practice & 6.76 \\
Spinal anaesthesia & 6.74 \\
Patient monitoring & 6.67 \\
Respiratory care & 6.64 \\
Epidural anaesthesia & 6.59 \\
iv fluids and acid base balance & 6.54 \\
Recovery room care & 6.50 \\
Preanaesthetic consultation & 6.46 \\
Obstetric anaesthesia & 6.46 \\
Intubation of the trachea & 6.39 \\
Premedication and preparation for anaesthesia & 6.05 \\
Local anaesthesia & 6.05 \\
Paediatric anaesthesia & 5.99 \\
Inhalation anaesthesia & 5.96 \\
The anaesthesia machine & 5.86 \\
Inhalation therapy and pulmonary physiotherapy & 5.86 \\
Deliberate hypotension & 5.82 \\
Continuing medical education issues & 5.39 \\
Neuro anaesthesia & 5.20 \\
The anaesthesia record & 5.18 \\
Cardiac anaesthesia & 4.91 \\
Chronic pain control & 4.86 \\
Teaching strategies & 4.61 \\
Statistical analysis, computers in anaesthesia & 4.38 \\
Research fundamentals & 3.67 \\
Hypnosis, acupuncture, electrical anaesthesia & 3.58 \\
\hline
\end{tabular}

ently ranked highest. They are regional nerve block, medicolegal considerations, acute pain control, anaesthesia for trauma surgery, anaesthetic implications of concurrent disease, complications of anaesthesia, critical care, thoracic anaesthesia, pharmacologic considerations and outpatient anaesthesia. The top five CME areas in terms of summed scores of need and interest are shown in Figure 2.

The relationship between perceived need, ideal expertise and current expertise to motivation score was explored. There was significant positive correlation $(r=0.83)$ between ideal expertise and motivation. There was also significant correlation $(r=0.65)$ between current expertise and motivation. In addition there is significant positive
TABLE IV

\begin{tabular}{lll}
\hline Subspecialties of anaesthesia & $\begin{array}{l}\text { Need } \\
\text { score }\end{array}$ & $\begin{array}{l}\text { Interest } \\
\text { score }\end{array}$ \\
\hline Paediatric anaesthesia & 2.0 & 6.0 \\
Anaesthesia for trauma surgery & 1.8 & 7.9 \\
Thoracic anaesthesia & 1.8 & 6.9 \\
Cardiac anaesthesia & 1.5 & 4.9 \\
Anaesthesia for the geriatric patient & 1.4 & 7.0 \\
Neuro anaesthesia & 1.3 & 5.2 \\
Outpatient anaesthesia & 1.2 & 7.2 \\
Obstetric anaesthesia and perinatology & 1.1 & 6.5 \\
\hline
\end{tabular}

TABLE V

\begin{tabular}{lll}
\hline Types of anaesthesia & $\begin{array}{l}\text { Need } \\
\text { score }\end{array}$ & $\begin{array}{l}\text { Interest } \\
\text { score }\end{array}$ \\
\hline Inhalation anaesthesia & 1.0 & 6.0 \\
Intravenous anaesthesia & 1.4 & 6.9 \\
Acute pain control (e.g., PCA service) & 2.7 & 7.3 \\
Regional nerve block & 2.7 & 7.3 \\
Chronic pain control & 2.3 & 4.9 \\
Local anaesthesia & 1.5 & 6.1 \\
Spinal anaesthesia & 1.3 & 6.7 \\
Epidural anaesthesia & 1.1 & 6.6 \\
\hline
\end{tabular}

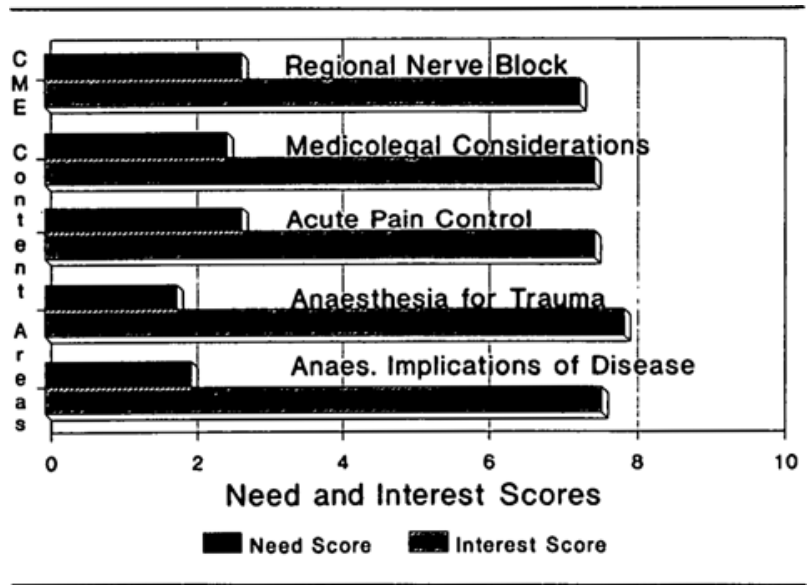

FIGURE 2 Top 5 content areas in terms of summed need and interest scores.

correlation between current expertise and ideal expertise $(r=0.95)$.

\section{Discussion}

Learning needs assessment is an important first step in systematic CME planning. It must serve as a starting point for planning and as a guide to programme evaluation. Furthermore it is a requirement for the accreditation of CME programmes in North America. ${ }^{2,9}$ A perceived learning need refers to a need identified by sampling the learner. This may be achieved by either quantitative 
methods such as chart reviews or examinations, or by qualitative methods such as surveys or interviews. In contrast to this, a prescribed need is identified or ascribed by a group of experts, or peer committee for the learners. Prescribed needs may likewise be measured quantitatively or qualitatively. For this study, perceived learning need was defined as the discrepancy between ideal and current expertise in each content area obtained by means of a survey of potential participants to $\mathrm{CME}$.

Adult learning theory states that adults need to know why they need to learn something before they undertake to learn it; and that they develop a readiness to learn things in order to cope with real life situations. ${ }^{13}$ It is also known that adults learn most effectively if learning is presented in the context of real-life situations, i.e., task- or problemcentered learning. In addition, the most potent motivators for adults to learn are those they identify for themselves, although they are also responsive to a lesser degree to those imposed upon them. ${ }^{13}$

The perceived need to learn is important because a person learns more effectively those things which he perceives as being involved in the maintenance of, or the enhancement of, the self. ${ }^{14}$ Learning is acquired through active involvement and is facilitated when the student participates actively in the learning process. Self-initiated learning is the most lasting and pervasive form of learning. These assumptions are applicable to CME because continuing medical education is a subset of adult education and doctors are a subset of adult learners. ${ }^{9,15}$

This study is the first assessment of the learning needs of anaesthetists. Needs assessment can serve as a starting point for planning, as a basis to modify and to evaluate the goals and objectives of $\mathrm{CME}$ programmes. CME planners, using the results of this needs assessment study as a guide, can ideally base their CME programme on the content areas with the highest perceived need scores. These areas are: regional nerve block, acute pain control, medicolegal considerations, chronic pain control, complications of anaesthesia, critical care medicine, anaesthetic complications of concurrent disease, paediatric anaesthesia, continuing medical education issues and pharmacological principles in anaesthesia.

Attendance or participation in CME programmes has been shown to be closely related to the physician's interest in specific topics. ${ }^{12}$ Results of our survey showed a high degree of correlation between interest-motivation score and ideal expertise level. This may mean that physicians have greater interest in content areas they identify as important to their practice. It would therefore not be wise to design CME programmes based on purely ideal expertise levels or interest-motivation scores. This study has shown that areas with high ideal expertise levels are associated with high current expertise levels $(r=0.95)$. It would appear that anaesthetists have a high degree of competence in these important content areas, thus the learning need for these areas would be low. Providing CME activities based on ideal expertise levels or interestmotivation scores would target the more trendy areas and thereby neglect areas of higher learning need.

Information on anaesthetists' interests or motivations would be important to CME planners who would want to improve participation or attendance to their programmes. They can structure their CME programme around content areas with the highest interest-motivation scores. These areas would be anaesthesia for trauma surgery, anaesthetic implications of concurrent disease, complications of anaesthesia, medicolegal considerations, regional nerve block, acute pain control, outpatient anaesthesia, critical care medicine, anaesthesia for the geriatric patient and thoracic anaesthesia. Other planners might want to balance their programme between content areas with high learning need and interests. These areas would be: regional nerve block, medicolegal considerations, acute pain control, anaesthesia for trauma surgery, anaesthetic implications of concurrent disease, complications of anaesthesia, critical care, thoracic anaesthesia, pharmacological considerations and outpatient anaesthesia.

Review of the literature failed to uncover any studies on the attitudes of physicians towards CME and specifically towards needs assessment. Needs assessment is a delicate topic that may be perceived as a threatening activity by some doctors. ${ }^{15}$ A qualitative assessment method and promise of anonymity was implemented in an attempt to lessen its impact. The $29 \%$ response rate to the survey is probably due to the sensitive nature of the topic of competence. A similar study on family physicians and general practitioners in the U.S. had a response rate of $32.2 \%{ }^{12}$ and probably reflects what should be expected for a survey of this type. A survey using quantitative assessment methods like an objective exam would probably be seen as even more threatening and its projected response rate might be even lower. The underlying assumption behind needs assessment surveys should be that those who respond to it would most likely participate in CME activities. As more and more CME providers design programmes around needs assessment data, physicians would eventually develop acceptance of the process.

More research must be done to explore the advantages and disadvantages of different learning need assessment methods. A more accurate measure of learning need may be achieved by combining both quantitative and qualitative methods. This study may provide the foundation for the development of a more extensive needs assessment instrument.

Physicians are a responsible group of adult learners. ${ }^{15}$ As practitioners engage in both formal and self-directed 
CME activity such as journal reading and peer discussion their learning needs change. Learning need is dynamic. Therefore, the results of learning needs evaluation cannot be assumed to be valid for a long period of time after the assessment. Needs assessment must be undertaken periodically, and there must be a quick and simple method for conducting the assessment. The methodology developed in this study is useful for this purpose.

In conclusion this study has demonstrated that needs assessment can be accomplished by a simple and quick method. The ability of CME planners to conduct learning needs assessment should hopefully improve the quality of CME programmes available to anaesthetists.

\section{References}

1 Ward J. Continuing Medical Education: Part 1. Introduction to the Series. Med J Aust 1984; 148: 20-2.

2 Escovitz GH, Davis D. A bi-national perspective on continuing medical education. Acad Med 1990; 65: 545-50.

3 Coldeway NA, Delisa JA. Educational needs assessment in physical medicine and rehabilitation - the foundation of continuing medical education. Arch Phys Med Rehabil 1983; 64: 391-5.

4 Batmangelish S, Demopoulos JT. Continuing health professional education - objectives and instructional strategies. Arch Phys Med Rehabil 1984; 65: 681-4.

5 Ward $J$. Continuing Medical Education: Part 2. Needs assessment in continuing medical education. Med J Aust 1988; 148: 77-80.

6 Burton JK, Merrill PF. Needs assessment-goals, needs, and priorities. In: Briggs LJ (Ed.). Instructional Design, New Jersey: Educational Technology Publications, 1977; 21-45.

7 Laxdal $O E$. Needs assessment in continuing medical education - a practical guide. J Med Educ 1982; 57: 827-34.

8 Currie DM. Self-directed learning and medical rehabilitation - a comparison. Arch Phys Med Rehabil 1985; 66: 454-6.

9 Fox $R D$. New horizons for research in continuing medical education. Acad Med 1990; 65: 550-1.

10 Dripps $R D$, Ecknhoff $J E$, Vandam $L D$. An Introduction to Anesthesia - The Principles of Safe Practice, 7th Ed. Philadelphia: WB Saunders, 1988.

11 Miller RD. Anesthesia 3rd edition. New York: Churchill Livingston, 1990.
12 Fox RD, Harvil LM. Self-assessments of need, relevance and motivation to learn as indicators of participation to continuing medical education. Med Educ 1984; 18 : 275-81.

13 Knowles $M$. The Adult Learner - A Neglected Species. 3rd Ed. Houston: Gulf Publishing Company, 1984.

14 Rogers $C R$. Client-Centered Therapy. Boston: Houghton Mifflin, 1965.

15 Ward J. Continuing Medical Education: Part 3. Doctors as Leamers. Med J Aust 1988; 148: 237-9. 